developing countries is thought provoking, and so is the paper on environmental standards at the workplace - and the options for setting standards in developing countries. The authors refer to the dilemma of proposing stricter environmental standards for developing countries, because of possible differences in the health status of the population in such countries, versus adopting some practical, achievable, less stringent standard which can be gradually raised. There is also a useful catalogue of vegetable dusts which cause lung disease in developing countries, a good classification of pesticides, and a debatable approach to medical surveillance for exposure to mineral dusts-which advocate medical examinations and chest radiology as a minimum for pneumoconiosis due to mineral dusts. The problem of acute pesticide poisoning and accidents at work in developing countries is highlighted, and these are clearly much bigger problems than in developed countries.

It is a fascinating book, well worth reading and definitely to be recommended as a standard text book for occupational health professionals in developing countries. It will also be an eye opener for occupational and public health physicians in developed countries with an interest in approaches to occupational health in the developing world.

T C AW

Occupational Medicine University of Birmingham

Environmental Epidemiology: Public Health and Hazardous Wastes. The National Research Council. (Pp 282; £29.95.) Washington DC: National Academy Press, 1991. ISBN 0-309-04496-0.

This book was written by a committee on environmental epidemiology and as a report for the board on environmental studies and toxicology in the Commission on Life Sciences of the National Research Council. It defines environmental epidemiology as "the study of the effect on human health of physical, biologic, and chemical factors in the external environment, broadly conceived". This area is an expanding field for which in 1987 the World Health Organization established a global environmental epidemiology network.

The committee was charged to review current knowledge of the human health effects caused by exposures to substances emanating from hazardous waste sites and to clarify and suggest how to improve the scientific bases for evaluating the effects of environmental pollution on public health, including specifically the conduct of health assessments at hazardous waste sites. This first report examines and evaluates the scientific literature, and develops recommendations about major data gaps that need to be remedied in order to advance the field. Despite repetition of some case histories and the difficulty for most readers of accessing the many unpublished cited reports, I found it particularly worthwhile reading. It focuses on one environmental health problem, develops a strategy for investigating and managing it, discusses policy issues, and ably demonstrates how environmental epidemiology can help to elucidate public concerns about possible health effects and the effectiveness of measures to mitigate them.
The committee concludes that despite the lack of adequate data with which to characterise the effects of hazardous wastes on public health in general, there is sufficient evidence that they have produced serious health effects in some populations. It notes too that identification, assessment, and ranking of hazardous wastes site exposures are at present inadequate, and that the overall impact on public health cannot be assessed.

A subsequent report will identify research opportunities and methodological issues, and will select and evaluate a sample of relevant non-peer-reviewed reports. I look forward to it and hope the committee will include with the case histories details of the environmental epidemiology methods used for their investigation and management. We all have much to learn.

ROBIN PHILIPP Department of Epidemiology and Public Health Medicine, University of Bristol

Preventive Medicine: A Report of a Working Party of the Royal College of Physicians. (Pp 212; £10.) London: Royal College of Physicians, 1991. ISBN 1-873240 32-5.

Those who feel that preventive medicine is the domain of all health professionals will be pleased that the Royal College of Physicians has produced a timely and well written report on the subject. The views of a number of specialties including medicine, genera practice, occupational medicine, and public health medicine were represented on the working party, which set out to provide objective guidance about the factual content of often controversial topics, and to assess the risks of different health problems and the costbenefits of preventive programmes. Practica steps which can be adopted by people generally and by health professionals to improve prospects of good health are described. Each chapter deals with a specific topic or part of the life cycle: smoking, cancer, infectious disease, accidents, occupational disease, childhood, and later life.

Although the report does not cover new ground, I found it a useful summary of existing evidence, well illustrated with graphs and tables. The recommendations at the end of each chapter vary from the very practical (eg how to give up smoking) to the rather al embracing type (eg, the need for better information systems). Some areas are not covered in any depth-screening in pregnancy, for example-but references are given to more detailed reviews. Other omissions, I feel, are less easily justified. Mental illness surely deserves to be included in such a review. I though that the attitude to one or two areas where prevention is needed is rather dismissive. For example the widely recognised role of harm reduction in prevention of $\mathrm{HIV}$ is not emphasised and advocating condoms seems to be discouraged, without supporting evidence, because "compliance is usually poor, especially among those most at risk".

Another omission which I feel deserves attention is the role of the clinician in referral and liaison with other agencies which have a crucial role in prevention-local authority departments and voluntary agencies in particular. This has relevance for areas covered such as accident prevention and social contact in later life.

Despite the criticisms outlined, this book will be useful for all clinicians-both undergraduate and postgraduate. It will also be of interest to those whose work is mainly about prevention-public health physicians and health promotion officers.

C QUIGLEY

Department of Public Health Medicine Trafford Health Authority Manchester

Developments in Biological Standardization. Vol 73. Ed International Association for Biological Standardization (Pp 386; price not stated.) Basel: Karger, 1991. ISBN 38055-5457-5

The mechanism of naturally acquired and vaccine induced immunity against $B$ pertussis remains elusive despite an ever increasing volume of technical and epidemiological publications on this fascinating subject. The latest collection of papers can be found in Developments in biological standardization, vol 73, where the proceedings of a symposium held in Tokyo in September 1990 are reported. Four of the eight sections are devoted to laboratory aspects of pertussis such as the molecular biology and genetics of the organism, the biological standardisation of acellular vaccines, and the development of antibody assay systems. These are specialist papers without immediate epidemiological relevance, although the work may eventually lead to novel applications such as genetically engineered vaccines containing non-reactogenic pertussis toxin, or possibly live attenuated vaccines. An essential step in developing improved pertussis vaccines is to identify the important protective antigens and the mechanism by which they induce immunity None of the animal work reported at the symposium sheds any real light on this problem or the reason why a serological correlate of protection has not been found in children vaccinated with acellular preparations. For the future, therefore, demonstration of efficacy in the field will continue to be essential for all new acellular preparations.

Although there is a section entitled "Clinical evaluation of vaccine efficacy" it contains little new information. Results from the post-trial follow up of children who took part in the Swedish efficacy trial in 1986 show that protection from acellular vaccines lasts for at least four years. However, more up to date results have now been published elsewhere. The two papers reporting the results of vaccine efficacy studies in Japan confirm earlier publications and illustrate the epidemiological problems inherent in trying to use routine surveillance data for such purposes. The difficulty in obtaining laboratory confirmation of cases, of ensuring unbiased reporting, and of identifying which acellular preparations have been used in the field raise doubts about the efficacy estimates presented and underline the importance of obtaining reliable efficacy data from 
controlled clinical trials before a new vaccine is introduced. With the recent increase in coverage for the existing whole cell vaccine and the consequent declining incidence of disease, there is now no opportunity to obtain such data in the United Kingdom. This inevitably raises the question of whether the sustained efforts of epidemiologists and laboratory workers that will be needed to bring the prospect of acellular vaccines into reality can be justified at a time when resources available for other aspects of health care are inadequate.

ELIZABETH MILLER Public Health Laboratory Service Communicable Disease Surveillance Centre London

The Health of the Nation: The BMJ View. Ed Richard SMith. (Pp 237; £9.95.) London: BMJ Publications, 1991. ISBN 0-72790314-4.

This book consists of 30 articles, plus some of the correspondence which followed published in the British Medical fournal in 1991 commenting on the UK government's consultation paper "Health of the Nation" The authors are in the main distinguished clinicians, with a few public health physicians, and three from the BMJ staff. The content is mostly hard to fault, but one might ask: why buy the book now? When published, the articles were topical comment intended to influence government thinking: but that was a year ago, and the definitive white paper is now out, leaving us with little else to do but spot the winners and losers.

I think the book will remain useful for a few years as a topic primer for students new to public health: not comprehensive, but covering a lot of interesting ground, and each article short enough to be read by the hard pressed student before a seminar. The government document was about a health strategy for England, so most of the comment in this book is about the English scene, which will limit its value elsewhere.

E G JESSOP

Wessex Institute for Public Health

\section{Short Reviews}

Health Systems and Public Health Medicine in the European Comunity. By Mark McCarthy and Sian Rees. (Pp 81; price not stated.) London: Royal College of Physicians, 1992. ISBN 1-873240-44-9.

The European Community has ensured mutual recognition between member countries of medical degrees, both for graduates and specialists, and the single market will require even closer cooperation for the transfer of pharmaceuticals and health insurance across national borders. This book provides an up to date account of the structure and financing of ambulatory and hospital care, and public health services of each of the $12 \mathrm{EC}$ countries. It describes the particular place of public health medicine in each country and discusses the need and opportunities for development and integration of training of this medical speciality.

Health Dimensions of Economic Reform. (Pp 68; SF15.) Geneva: WHO, 1992. ISBN 92-4-156146-7.

There has been some complacency with regard to ill health following on indus trialisation, greater life expectancy, and the far reaching changes in lifestyles and values now taking place. This book analyses how health can become an essential component of socioeconomic decision making. It illustrates how objectives for the protection and improvement of health status and quality of life can be defined at the very outset along with macroeconomic objectives, and that processes of adjustment can achieve both sets of objectives simultaneously.

Handbook of School Health. Medical Officers of Schools Association. (Pp 236; £18.95.) Trentham Books, 1992. ISBN 0948080-66-3.

The Handbook is the regular official publication of the Medical Officers of Schools Association and covers all aspects of the health and medical care of school children The new and entirely revised 1992 edition deals with many school medical issues and contains chapters on preventive medicine immunisation and examinations, psychology and psychiatry of childhood, sports injuries, safety and adventure activities. The Handbook is written in an accessible style and may be read by nurses and teachers as well as by doctors concerned with school medical services.

International Statistical Classification of Diseases and Related Health Problems-10th Revision 1992. (Pp 1243, \$US117.) Geneva: WHO, 1992. ISBN 92-4 154419-8.

The 10th revision of ICD now available reflects the classification's continuing refinement and expansion. Conditions have been regrouped in order to increase the level of clinical detail and enhance ease of use while retaining the classfication's sensitivity for its traditional epidemiological and statistical uses. It is now presented in three separate volumes, allowing independent access to the tabular list; all related definitions, standards, rules and instructions; and the alphabetical index. ICD 10 comes in to force on 1 January 1993.
NOTICES

International Conference: "1993, The European Year of the Elderly: Healthy Aging". Date: 18-20 March 1993; place: World Trade Centre Rotterdam; contact address: SOGG, PO Box 23115, $3001 \mathrm{KC}$ Rotterdam, The Netherlands; tel 3110436 7577, fax 31104367273 .

International Conference on Chronic Diseases and Changing Care Patterns in an Aging Society. Date: 9-11 June. 1993. Place: Amsterdam, The Netherlands Deadline for abstracts: October 31, 1992. Further details from: Dr Trudi van den Bos, Institute of Social Medicine, University of Amsterdam, Meibergdreef 15, 1105 AZ Amsterdam, The Netherlands; tel 3120 5664707; fax 31206912401 .

10th International Conference on Quality Assurance in Health Care. Date: June 20-23, 1993; place: Maastricht, The Netherlands; contact address: Conference Agency Limburg, PO Box 1402, 6201 BK Maastricht The Netherlands; tel 3143 619192, fax 3143 619020 .

13th Scientific Meeting of The International Epidemiological Association: "New Pathways in Epidemiology". Date: September 26-30, 1993; place: Sydney, Australia; contact address: Conference Secretariat, 13th Scientific Meeting of the IEA, PO Box 746, Turramurra 2074, NSW Australia; tel 612449 1525, fax 6124887496 .

The 24th International Congress on Occupational Health will take place in Nice, France, on September 26-October 11993. The aims of the congress are to bring together professionals in occupational medicine from around the world and to promote the development of scientific knowledge in the field. For further information contact: C 24 France, "Les Miroirs", Cedex 27, 92096 Paris La Defense, France. Tel 33-1 476233 70; Fax 33-1 47623153.

6th International Congress for Infectious Diseases. Date: April 26-30, 1994; place: Prague, Czechoslovakia; contact address: Norman $\mathbf{R}$ Stein, Internationa Society for Infectious Diseases, 180 Longwood Avenue, Boston, MA 02115, USA. Tel 617-432-2270; Fax 617-731-1541. 